\title{
Transformación digital $y$ museos sin fronteras. Una evaluación de siete museos de la ciudad de Lima en tiempos de pandemia
}

\author{
Digital transformation and museums without borders \\ A evaluation of seven museums of Lima city in pandemic times
}

(i) Fernando Pino Apablaza ${ }^{\square}$
${ }^{1}$ Universidad Le Cordon Bleu. Lima, Perú

Recibido: 20/05/2021 Revisado: 18/06/2021 Aceptado: 21/06/2021 Publicado: 31/ 06/2021

\section{RESUMEN}

La investigación es de alcance descriptivo. Tuvo como objetivo, conocer los niveles de uso, respecto a las tecnologías digitales de siete importantes museos de la ciudad de Lima. Se consideró dos dimensiones tecnológicas. Una denominada tecnología digital in situ, que son aquellas aplicaciones tecnológicas digitales que están dentro del espacio físico del museo, y la otra dimensión denominada tecnología digital vía remota, que se usa para dar acceso al museo desde afuera del espacio físico. Además, se presenta un breve marco teórico sobre transformación digital, donde se describe a una sociedad líquida que se diluye en plena revolución digital. La hipótesis apunta a que existen aún deficiencias en el uso de las tecnologías digitales en los siete museos del Centro Histórico de Lima. Los resultados obtenidos fueron moderados, demostrando frugalidad por parte de los museos en el uso de las tecnologías digitales. En conclusión, existen brechas digitales aún por subsanar en estos museos, que son los más importantes de la ciudad de Lima, la economía es un factor limitante en la digitalización de los museos, y aún existen reticencias y letargo por abordar la transformación digital. Palabras clave: Museos, transformación digital, tecnologías digitales, aceleración digital.

\section{ABSTRACT}

The research was descriptive. Had like objective, know the usage levels about digital technologies of seven importants museums of Lima city. Were considered two thechnological dimensions. One that was called digital technologies in situ, because its are within the fisical space of museum, and the other dimensión called digital technologies via remote, wich are, give access from the space outside the museum. Also show a short theoretical framework, that describe how the liquid society diluted in plenty digital revolution. The hypothesis indicate a low level about the usage of digital technologies in the museums of Historic Center of Lima. The results were moderate, showing frugality by museums in 
the usage of digital technologies. In conclusion, in the most importante museums of Lima city, exist digital gaps yet for remedy. The economy is a limiting factor in the digitization of museums and exist yet reticences and lethargy to board the digital transformation.

Keywords: Museums, digital transformation, digital technologies, digital acceleration.

\section{INTRODUCCIÓN}

En estos tiempos de pandemia por el COVID-19, donde la gran mayoría de autoridades han exhortado incansablemente a sus comunidades a que se practiquen medidas de confinamiento como la cuarentena obligatoria para salvaguardarse de una posible infección, ha ocurrido un fenómeno llamado aceleración digital. Y esta situación que no permite salir de casa, ha llevado a las personas a que aprendan vertiginosamente a realizar la mayoría de sus obligaciones por la web, como lo son: el pagar deudas, comprar comida, estudiar, laborar, consultar al médico, etc. Sin dejar de lado las acciones que se realizan en tiempos de ocio como lo son: ir al teatro, asistir a un concierto de música o visitar museos. La aceleración digital que vivimos ha hecho aún más notoria esta nueva configuración del mundo, donde existen nítidamente dos partes, por un lado los usuarios, que son las personas que requieren de estos servicios digitales y por el otro lado están las organizaciones, que necesitan imperativamente digitalizarse, si quieren sobrevivir en un entorno cada vez más competitivo, donde la transformación digital ya no parece ser una simple opción.

Esta aceleración digital, ha destapado una realidad en algunos sectores, como es natural en algunos más que otros. En el caso del sector financiero se puede observar que, los bancos no han perdido el tiempo en subirse a la ola digital. Pero en el sector de las industrias culturales en Lima, donde se encuentran ubicados los museos, el abordaje a la transformación digital aún es lento, en relación a toda la gama de posibilidades que las tecnologías digitales pueden ofrecer.

Según Bermúdez (2018) en el Perú, un país con una población de 32551815 habitantes, son usuarios de internet, aproximadamente 22 000000 habitantes, que no necesariamente tienen internet en casa. Según el Instituto Nacional de Estadística e Informática (INEI), al 2019 solo indicó que solo el 35 \% de los hogares tienen acceso a internet. Además del total de la población de seis y más años de edad que usa internet, el 94,5\% de la población navega en internet para obtener información, el $83,0 \%$ lo utiliza para comunicarse (correo o chat) y el $66,0 \%$ recurre a internet para realizar actividades de entretenimiento.

Existen en internet interesantes alternativas que permiten acceder a la variada oferta de actividades de entretenimiento, como es el caso de los museos digitales. Museos que se desarrollan en espacios virtuales, y al igual que los museos físicos, buscan perpetuamente transmitir la cultura de generación en generación a través de procesos de comunicación, como es naturalmente en estos días, haciendo uso de las tecnologías de la información y comunicación (TICs). Y es indudable que el buen uso de estas tecnologías traerá consigo grandes oportunidades a las organizaciones. En el caso de los museos, estas tecnologías, los posibilitarán de mostrar sus contenidos al mundo. Otro beneficio que obtendrán será mayor cantidad de visitas y por lo tanto, cum- 
plirán con mayor magnitud su misión institucional, gracias a los públicos que se conecten vía online, que cada vez son más.

Entonces, es evidente que no solo los museos salen ganando con estas nuevas tecnologías, la comunidad global también. Gracias a estas tecnologías digitales, las distancias geográficas parecen acortarse, y paradójicamente permiten a los individuos evitar el desplazamiento real, para recorrer un espacio virtual. Por su puesto que la virtualidad no remplazará la experiencia real, pero le otorgará al visitante un acercamiento importante a un espacio donde se podrá informar, entretener y hasta opinar desde un blog a miles de kilómetros de distancia, sin importar fronteras. En este mismo sentido García (2019) menciona "las tecnologías digitales, asociadas a la globalización socioeconómica y cultural, fomentan certezas de lo que ganamos: más información y entretenimiento diversificado, espacios para debatir y participar, acceso a bienes, mensajes y servicios no disponibles en la propia nación" (p.11).

Según información del Ministerio de Cultura MINCUL (2012), en la ciudad de Lima existen un total de 65 museos. De esta población se escogió intencionadamente a los que se consideran los museos más importantes y representativos de la ciudad de Lima. Se seleccionó a 7 museos de diferente naturaleza, entre ellos museos de arqueología, museos de antropología y museos de arte. Este grupo de museos fue seleccionado teniendo en cuenta criterios como la cantidad de visitas físicas y virtuales que reciben y además su importancia histórica dentro del proceso identitario nacional.

\section{La sociedad y la transformación digital}

No se puede negar, que hoy en día en tiempos de pandemia por el nuevo Coronavirus, se ha hecho más notorio que nunca, la imperiosa necesidad del uso de las tecnologías digitales, pero en realidad este imperioso uso tecnológico no es solo de ahora, sino que deviene de un fenómeno llamado revolución digital, que ha traído consigo una serie de significativas transformaciones en un mundo cada vez más globalizado. En este sentido Montiel (2004), menciona que:

Una de las características más visibles y trascendentes de la mundialización la constituye el surgimiento de una cultura global inédita, de un magma pluricultural generado por las nuevas tecnologías de la información y comunicaciones, que da nuevas dinámicas, procesos y escenarios culturales (p.47).

Escenarios culturales como lo son los museos digitales, que en estos tiempos de pandemia han sido visitados más que nunca, ya sea desde una computadora o un teléfono móvil conectado a internet, que como bien dice Benito (2019) "teléfonos móviles sin los que no podemos vivir en sociedad" (p.467).

Dato que nos llamó la atención, fue la cantidad de individuos que visitaron los museos del Perú, desde la plataforma digital del MINCUL, que hasta finales del mes de mayo, fue de un millón de vistas, de los cuales cuatrocientos mil corresponden al periodo de cuarentena obligatoria. Por supuesto que hay que considerar que en estos tiempos en los que vivimos, se produce en el mundo una 
aceleración digital, que tiene un reflejo en el incremental uso de las tecnologías digitales, pero tampoco es de sorprenderse, ya que también se sabe que en estos tiempos, la sociedad cambia y se amolda a las circunstancias, como si fuera líquida. Como decía con acierto Bauman (2013) "ninguna de las etapas consecutivas de la vida social puede mantener su forma durante un tiempo prolongado" (p.17).

En este mundo globalizado, aquellos seres humanos que tengan acceso a las tecnologías digitales, experimentarán cada vez más, nuevas formas de hacer las cosas, hasta los grupos más reticentes a las tecnologías digitales como es el caso de los baby boomers ${ }^{1}$, que son adultos mayores, que superan los 57 años, se están subiéndose a esta ola digital. En este sentido Montiel (2004) afirma que "el gigantesco desarrollo de las industrias de la información, de las telecomunicaciones y del audiovisual, potenciadas ahora por la revolución digital, ha provocado transformaciones estructurales en las sociedades actuales, y dado lugar a nuevas formas de experiencia humana" (p.48). Mientras que para, Mst (2017) "las tecnologías digitales, se han ido incorporando más en nuestras vidas y han impactado en el funcionamiento de instituciones como el Estado, la empresa y la familia" (p.23). Y todo esto antes mencionado se refleja con naturalidad en el día a día, de la gran mayoría de ciudadanos de todas las edades. Por ejemplo, las personas de la tercera edad tienen que utilizar en tiempos de pandemia las consultas médicas vía web, los adultos tienen que trabajar vía remota desde sus casas haciendo uso de las conferencias Zoom, los jóvenes estudiantes universitarios estudian también a través de plataformas digitales, al igual que los estudiantes de la educación básica regular y los niños del pre escolar. Entonces toda esta variedad de individuos denominados como inmigrantes y nativos digitales, serán usuarios de las tecnologías, algunos más por obligación, como es el caso de los inmigrantes digitales y otros más por diversión, como es el caso de los nativos digitales ${ }^{2}$. Ambos grupos en cierta manera coaccionados por los inevitables cambios que trae consigo la revolución digital ${ }^{3}$. Según Nicolás Negroponte, director del Instituto Tecnológico de Massachussetts (MIT), como se citó en Mejía (2018), afirma que:

Existe en estas últimas décadas, una aceleración del vibrar neuronal de la humanidad. A causa de este aceleramiento se dice que la humanidad, en los últimos cien años, ha producido mucho más ciencia y tecnología que todo el conjunto de saberes acumulados por el hombre en toda su historia (p.46).

Entonces, es plausible que cada vez más, la ciencia y la tecnología están avanzando concomitantemente, creando innovaciones tecnológicas para facilitar la vida de los seres humanos, generando nuevas experiencias gratificantes. Por ejemplo el uso de los hologramas en los museos.

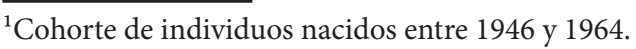

${ }^{2}$ Individuos que han crecido en plena era digital.

${ }^{3}$ Individuos nacidos en la era pre digital, que han tenido que aprender y adoptar las tecnologías digitales.
} 
Transformación digital y museos sin fronteras. Una evaluación de siete museos de la ciudad de Lima en tiempos de pandemia

Pino, F.

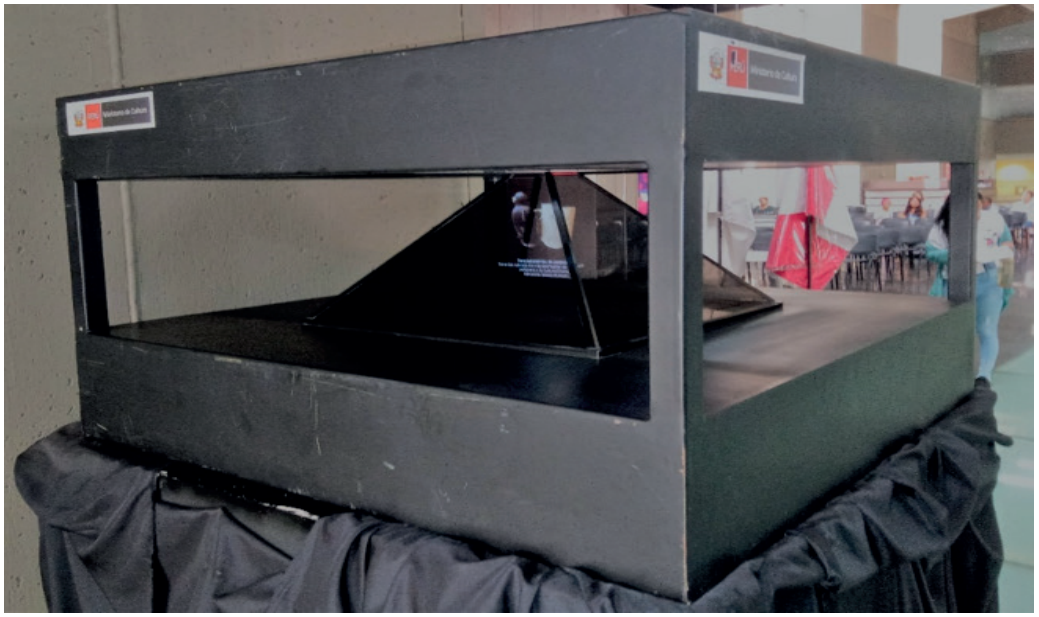

Fuente. Archivo personal, (2020).

Figura 1. Holograma en el Museo de la Nación de Perú.

Otro ejemplo, sería el caso del Museo Estatal virtual en 360 grados, que permite al viHermitage de San Petesburgo en Rusia, que sitante observar gran parte de su cocuenta con una interesante y extensa visita lección, distribuida en sus tres pisos.

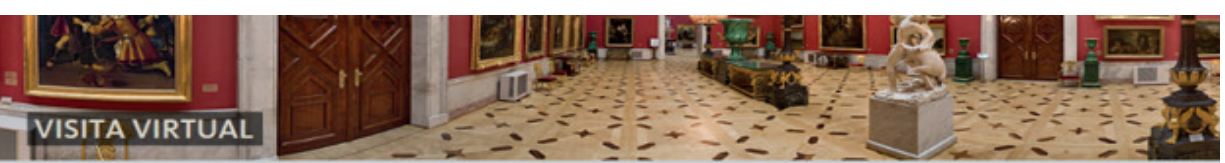

\section{El complejo principal del museo}

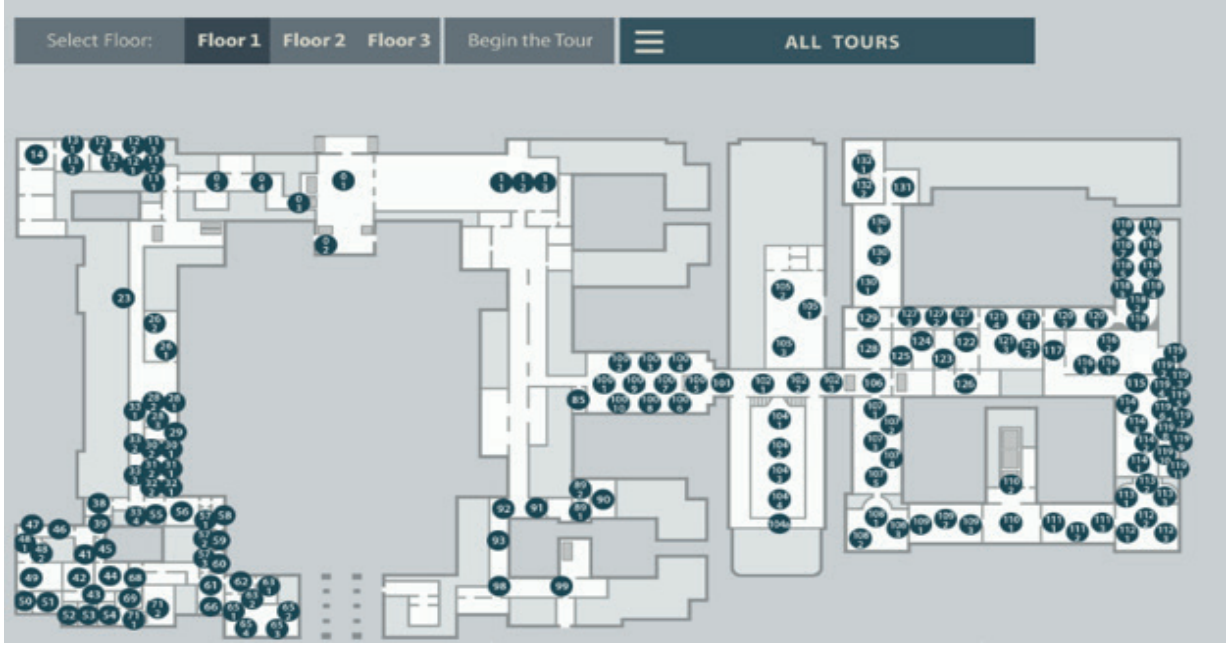

Fuente: página web del Museo Estatal Hermitage, (2020).

Figura 2. Visita virtual de tan solo el primer piso del Museo Hermitage de San Petesburgo. https://www.hermitagemuseum.org/wps/portal/hermitage/panorama/virtual_visit/ panoramas-m-1/?!ng=es 
Otro buen ejemplo, también lo da el Museo Nacional del Prado en España, que presentó en tiempo real a través del Facebook, vía streaming, su contenido titulado
¿Cómoserestauraunaobra?Tomandocomomodelo La Anunciación, obra del famoso pintor del periodo del quattrocento italiano Fra Angélico.

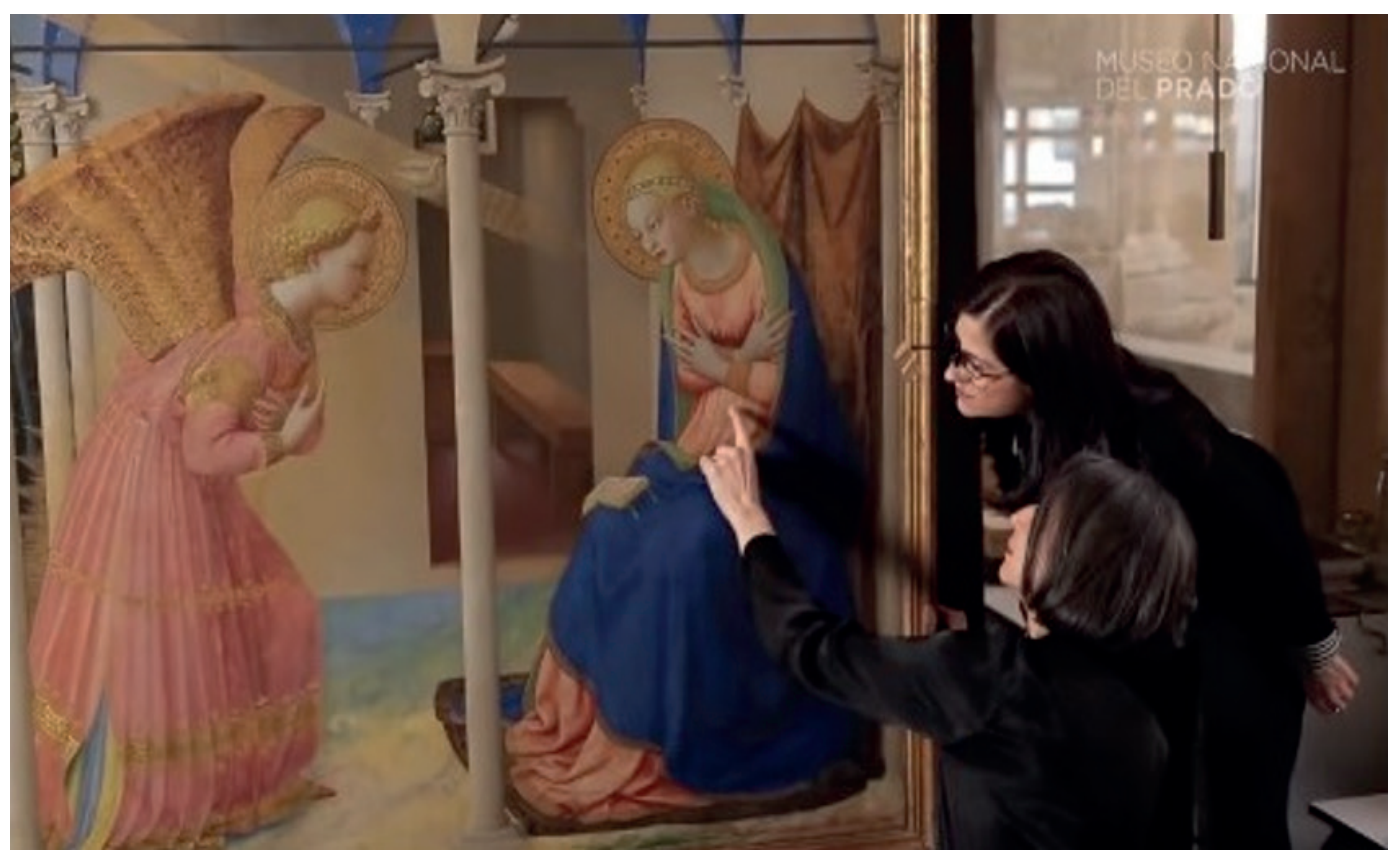

Fuente: Facebook del Museo Nacional del Prado, (2020).

Figura 3. Transmisión vía streaming de la restauración de la capa pictórica de la obra La Anunciación

La transformación digital en los museos del Perú

La realidad sobre la transformación digital en el Perú, es que esta se ha dado de manera tardía. Así lo afirma un experto de la empresa consultora KPGM "las tecnologías son los medios para que se cristalice la transformación digital, y el empresariado peruano es reticente, y la transformación digital es aun lenta" (Zegarra, 2018). Esta realidad no es ajena a los museos del Perú, que han tenido un abordaje lento a la transformación digital.
Y es que recién en Abril del 2020, a inicios de la pandemia por el nuevo coronavirus, solo un puñado de museos a cargo del MINCUL, han presentado acciones tecnológicas, buscando la digitalización. Según Claudia Pereira, directora general de museos del MINCUL, precisó "Estamos seguros que después de acatar las disposiciones establecidas para prevenir la propagación del COVID-19, esta es una buena alternativa, que permitirá que los estudiantes, turistas y público en general puedan visitar de manera virtual nuestros museos". (Gob.pe, 2020). 


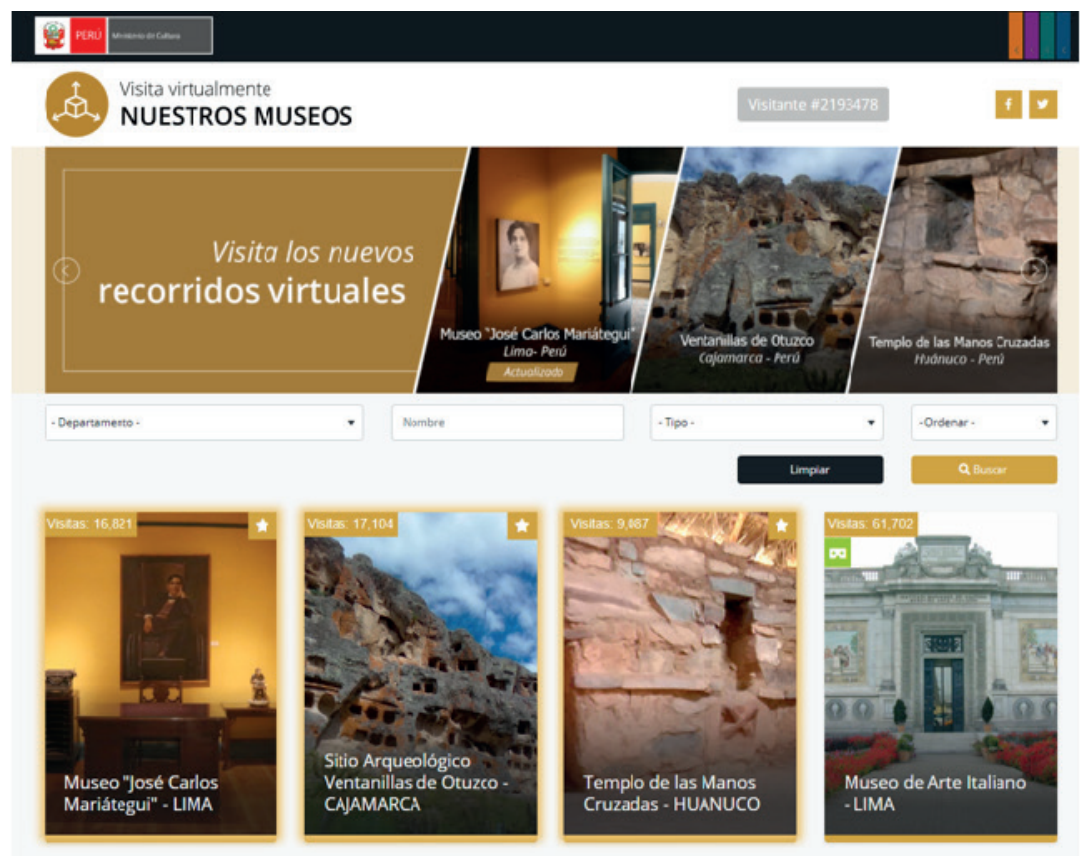

Fuente: Extraída de la página web del MINCUL, (2020).

Figura 4. Plataforma de museos digitales del MINCUL.

Un factor que aletarga aún más la transformación digital de los museos en el Perú, es el factor económico. En este sentido Riofrío (2019), afirma que "los museos requieren destinar importantes recursos para el mejoramiento de infraestructura de salas expositivas, equipamiento de depósitos; así como para la conservación, restauración, digitalización e investigación de sus colecciones". Y lamentablemente en el caso peruano siguiendo a Riofrío "los museos carecen de fondos económicos para operar en el día a día y abordar proyectos importantes de largo plazo resulta inviable". Y como corolario "en cuanto a la innovación tecnológica, los museos presentan bajos porcentajes en el uso de nuevas tecnologías. Por un lado, en relación a las tecnologías de la información, se trata de un sector conectado en la web y a las redes sociales, pero no se puede considerar como un sector digitalizado, ya que existen pocas iniciativas de uso de herramientas digitales como aplicaciones mó- viles y apertura digital de las colecciones para diversificar las experiencias de acercamiento de los visitantes a las colecciones" (pp. 7-18).

Todo esto antes mencionado, es parte de la realidad problemática que se vive en los museos del Perú. Un país pluricultural y mega diverso, lleno de expresiones culturales y naturales pero con un lastre de décadas de malas gestiones y desgobiernos que no han tenido la voluntad ni el suficiente interés de mejorar la cuestión cultural. Bien como decía el ya extinto sabio naturalista Antonio Raimondi "El Perú es un mendigo sentado en un banco de oro".

\section{Los museos y la gestión del cambio}

En esta era digital en la que vivimos, se han experimentado grandes cambios y muchos de ellos se han dado a causa del internet. Según Negroponte (1995). 
El agente del cambio será Internet, en sentido literal y metafórico. Internet es interesante no sólo en tanto que red global masiva y omnipresente, sino también como algo que parece haber evolucionado sin un diseño previo y que presenta un aspecto parecido a la formación de una bandada de patos. No existe ningún jefe, pero todas las piezas encajan admirablemente (p.110).

Los museos como cualquier otra organización, deben aprender a adaptarse a los inevitables cambios que se presentan en el mundo. Aquellos museos que no gestionen cambios, estarán dejando mucho que ganar, mientras que los museos que sí lo hagan, se fortalecerán, y serán mejor vistos ante sus públicos. Por lo tanto los museos a través de sus directores deberán tomar decisiones y gestionar cambios, sobre todo en estos tiempos de pandemia y revolución digital. Para Senge (2010) “este es pues el significado básico de organización inteligente, una organización que aprende y continuamente expande su capacidad para crear su futuro" (p.24). Un futuro que traerá consigo más cambios, que bien se le presentarán a los museos como oportunidades o amenazas.

Según Finlev et al. (2017), expertos consultores del Banco Interamericano de Desarrollo (BID), mencionaron que "en la década por venir, los artistas, las industrias creativas y culturales, añadirán nuevos medios digitales y físicos a su conjunto de instrumentos" (p.3). Entonces los museos como parte de las industrias culturales deberán estar alertas a los próximos cambios que están por venir. Mientras tanto el BID, pensando en ayudar a solucionar la problemática de los museos frente a la pandemia, lanzó en junio del 2020 la plataforma Open Museum, a la cual se puede ingresar dando click en http://www.ibermuseos.org/recursos/noticias/bid-lanza-plataforma-para-apoyar-a-los-museos-en-tiempos-decovid-19/

Entonces, está claro que hoy en día los museos en medio de esta revolución digital están casi obligados a digitalizarse, para así poder responder eficientemente a las nuevas necesidades que demanda la sociedad en la que se encuentran insertados. Pero no solo deberán responder a la sociedad con la cual comparten cultura, sino más bien a una sociedad global. En este sentido Maceira (2009) afirma que "los museos enfrentan ciertos retos para responder a las nuevas demandas y expectativas de la sociedad, así como a las condiciones del mundo contemporáneo" (p.7). Por lo tanto, los museos que aún no han aplicado acciones tecnológicas para digitalizarse, deberían poner de inmediato en sus agendas, la planificación de una estrategia digital, estrategia que coadyuvará a que el acercamiento de los visitantes en tiempos de pandemia sea una realidad, aunque sea de manera virtual. Una vez que los museos tengan la iniciativa de abordar con convicción la transformación digital, se les presentarán un conjunto de opciones a escoger, como lo son las redes sociales o la creación de la página web. Estas serán buenas oportunidades, para que los museos no estén solo en vista de su comunidad más próxima, sino también en vista del mundo. En este mismo sentido Mas (2018) afirma:

En los últimos años, la irrupción de las tecnologías digitales obliga a los museos no sólo a tratar de aprovechar estas nuevas posibilidades sino también a procurar optimizarlas para fortalecer la 
consecución de un museo que sea más social, participativo y colaborativo, en línea con lo que están haciendo también otras instituciones culturales. En este contexto, las redes sociales en general y Facebook en particular pueden ofrecer muchas oportunidades (p.185).

Todas estas ideas antes mencionadas, convergen en un ideal que El Consejo Internacional de Museos (ICOM), presenta en el portal principal de su página web https://icom.museum/es/ donde expresa textualmente que: "Los museos no tienen fronteras; tienen una red", metáfora que hace alusión a las nuevas tecnologías digitales, de las que pueden hacer uso los museos para llegar a la comunidad global. En este mismo sentido Monika Hagedorn Saupe, directora de Europeana, advierte que "para muchas personas, los museos que hoy en día no están en la red, no existen" (Hagedorn Saupe, 2014).
Según Alemán (2006), afirma que "los museos deben ser mediadores entre el patrimonio y la comunidad" (p.16). Mediadores asimiladores del cambio que deben estar presentes en la web, a través de plataformas digitales, para así acortar las brechas existentes entre la comunidad global y el patrimonio. En este mismo sentido Elisondo et al. (2015) afirman que "las tecnologías de la información permiten que las personas puedan acceder a información sobre ciertos conjuntos patrimoniales culturales y naturales a los que de otra manera no lograrían entrar" (p.18). Por lo tanto, estas nuevas tecnologías contribuyen en gran parte con la misión de los museos. Misión que tiene que ver con la investigación, conservación, difusión, exhibición y transmisión de contenidos para beneficio de la sociedad, o como bien mencionan Reginald et al. (2012) "en beneficio de la comunidad donde se ubican y de los visitantes foráneos" (p.10). Para observar las misiones institucionales de museos nacionales ver (tabla 1).

Tabla 1. Misiones institucionales de museos nacionales

\begin{tabular}{|c|c|}
\hline Museo & Misión institucional \\
\hline $\begin{array}{l}\text { Museo Nacional de } \\
\text { Arqueología, } \\
\text { Antropología } \\
\text { Historia del Perú }\end{array}$ & $\begin{array}{l}\text { Según (Museo Nacional de Arqueología, Antropología e Historia del Perú, } \\
\text { s.f.), su misión es crear conciencia en la comunidad peruana y mundial del } \\
\text { valor de nuestro patrimonio, fortaleciendo los valores nacionales a través } \\
\text { del conocimiento, identificación y difusión de nuestra cultura y promoviendo } \\
\text { la ciudadanía intercultural. } \\
\text { Recuperar, conservar, investigar y dar tratamiento al material histórico } \\
\text { arqueológico para su puesta en valor, favoreciendo el estudio de } \\
\text { investigadores interesados en el pasado peruano Informar, educar y facilitar } \\
\text { un mayor acceso a la población a los productos culturales y artísticos que } \\
\text { alberga a través de exposiciones museográficas permanentes, temporales } \\
\text { e itinerantes, y de material educativo. } \\
\text { Renovar el conocimiento del pasado peruano y fortalecer la identidad } \\
\text { nacional, a través de la divulgación de los resultados de las investigaciones } \\
\text { dentro y fuera del Perú. } \\
\text { Prestar los servicios de asesoramiento, estudio, información o dictamen de } \\
\text { carácter científico o técnico que le sean requeridos. }\end{array}$ \\
\hline $\begin{array}{l}\text { Museo Histórico } \\
\text { Nacional de Chile }\end{array}$ & $\begin{array}{l}\text { Según (Museo Histórico Nacional de Chile, s.f.), su misión es facilitar a la } \\
\text { comunidad nacional e internacional el acceso a la comprensión de la } \\
\text { historia del país, permitiendo el reconocimiento de las diversas identidades } \\
\text { que lo constituyen y han dado forma a Chile, desde su pasado } \\
\text { precolombino a su conformación política y territorial. }\end{array}$ \\
\hline
\end{tabular}




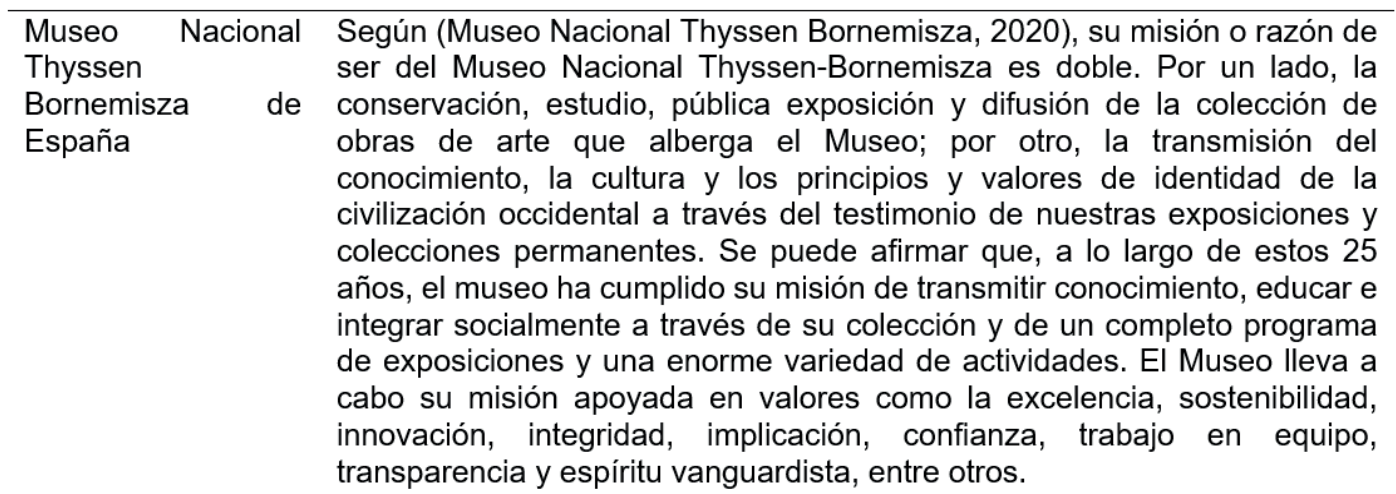

Museo Nacional del Según (Museo Nacional del Virreinato, 2019), su misión es conservar, Virreinato de investigar, exhibir y difundir la colección e inmueble que resguarda el Museo México Nacional del Virreinato conforme a perspectivas de rigor académico, apertura a las necesidades de los públicos y con la finalidad de enriquecer la visión que sobre el patrimonio histórico virreinal se tiene en México y en el mundo.

Museo Nacional de Historia americana Smithsonian

\begin{abstract}
Según (Museo Nacional de Historia Americana, s.f.), su misión es empoderar a las personas para crear un futuro justo y compasivo explorando, conservando y compartiendo las complejidades de nuestro pasado. [...] Nuestro sitio web ofrece exhibiciones en línea, vistazos de la organización previa de nuestras colecciones, y un resumen de los programas y las actividades del Museo. Con el sitio web, usted puede planificar su visita al Museo o hacer un recorrido virtual desde su hogar. Smithsonian's History Explorer, nuevo sitio web en inglés, tiene muchos materiales educativos para enseñar y aprender sobre la historia estadounidense. Lea nuestro blog, "O Say Can You See," para descubrir lo que está pasando actualmente en el museo.
\end{abstract}

Como se puede observar, todas las misiones institucionales de los museos nacionales, declaran sus acciones medulares como lo son: investigar, conservar, difundir, exhibir. Acciones que son común denominador en las misiones institucionales de los museos, pero hay que advertir que no son las acciones del museo las que cambian, lo que cambia es la forma de cómo ejecutar las acciones. Entonces la diferencia está en la aplicación de las tecnologías digitales, que sin duda alguna cambian exponencialmente la forma de ejecutar los procesos de difusión, exhibición y comunicación. En este sentido Nuñez (2007) afirma que "es importante tener conciencia del proceso, siendo necesario que la exposición sea concebida desde la perspectiva de la comunicación" (p.198), comunicación que se transmite desde los espacios físicos del museo, pero que en esta era digital también debería a la par ser transmitida en forma virtual a través de la web. 
También hay que destacar, que de todas las misiones que se presentan en la tabla 1 , solo una que corresponde al Museo Nacional de Historia Americana Smithsonian, presenta en su declaración acciones digitales, que incluye página web, y uso del social media, disponiendo un blog propio para mejorar la comunicación con sus públicos. Entendiendo a la social media como lo explica Moreno (2018):

Es el conjunto de plataformas y medios de comunicación que permiten el intercambio de mensajes y la interacción entre individuos y marcas. Entre esas herramientas se encuentran las redes sociales, pero también otras como los blogs o los foros de internet, es decir, todas las que surgen con la popularización de la web 2.0 a principios del siglo XXI $\mathrm{y}$ que permiten que cualquier persona pueda expresar su opinión en internet de forma rápida y sencilla. Gracias a los medios sociales, nunca antes había sido tan fácil estar conectado con el resto del mundo. Estas plataformas, entre las que se encuentran las redes sociales, permiten hablar e interactuar con otros individuos, pero también con marcas y compañías. (p.11)

\section{Metodología de la investigación}

La investigación se realizó bajo el enfoque cuantitativo. Además es de alcance descriptivo. La muestra correspondió a 7 de los museos más importantes del Centro Histórico de Lima, trabajando de manera anónima para no repercutir en su imagen institucional. El levantamiento de datos se realizó de manera física y digital. De manera física se habían visitado los museos antes de la pandemia, y de manera virtual en tiempos de pandemia. Se fabricó un instrumento de recolección de datos que permitió comprobar la hipótesis de investigación que se muestra a continuación.

\section{Instrumento de recolección de datos} A continuación, se presenta el instrumento de recolección de datos, donde se puede observar en la tabla 2, los resultados de cada uno de los museos evaluados.

Tabla 2. Instrumento de recolección de datos

\begin{tabular}{|c|c|c|c|c|c|c|c|c|}
\hline Tecnologías & $\begin{array}{l}\text { Puntaje } \\
\text { por } \\
\text { tecnología }\end{array}$ & Museo 1 & Museo 2 & Museo 3 & Museo 4 & Museo 5 & Museo 6 & Museo 7 \\
\hline \multicolumn{9}{|c|}{ Tecnologias in situ } \\
\hline $\begin{array}{l}\text { Conexión wi- } \\
f i\end{array}$ & $1 \mathrm{pts}$. & 1 & 1 & 1 & 1 & 1 & 1 & 0 \\
\hline Auto guías & $1 \mathrm{pts}$. & 0 & 1 & 0 & 1 & 0 & 0 & 0 \\
\hline $\begin{array}{l}\text { Códigos de } \\
\text { respuesta } \\
\text { rápida }\end{array}$ & $1 \mathrm{pts}$. & 0 & 1 & 0 & 0 & 0 & 0 & 1 \\
\hline $\begin{array}{l}\text { Realidad } \\
\text { virtual (3D) }\end{array}$ & 1 pts. & 0 & 0 & 0 & 0 & 1 & 0 & 0 \\
\hline Hologramas & $1 \mathrm{pts}$. & 1 & 0 & 1 & 0 & 1 & 0 & 0 \\
\hline $\begin{array}{l}\text { Sub total de } \\
\text { tecnologías } \\
\text { in situ }\end{array}$ & & 2 & 3 & 2 & 2 & 1 & 1 & 1 \\
\hline
\end{tabular}




\begin{tabular}{|c|c|c|c|c|c|c|c|c|}
\hline \multicolumn{9}{|c|}{ Tecnologías vía remota } \\
\hline Página web & $1 \mathrm{pts}$. & 0 & 1 & $\mathbf{0}$ & 1 & 0 & 1 & 1 \\
\hline Streaming & $1 \mathrm{pts}$. & 0 & 1 & 1 & 1 & 1 & 1 & 1 \\
\hline $\begin{array}{l}\text { Redes } \\
\text { sociales }\end{array}$ & 1 pts. & 0 & 1 & 1 & 1 & 1 & 1 & 1 \\
\hline $\begin{array}{l}\text { Recorridos } \\
\text { virtuales }\end{array}$ & $1 \mathrm{pts}$. & $\begin{array}{llll}0 & & & \\
\end{array}$ & 1 & 1 & $\begin{array}{llll}0 & & & \\
0\end{array}$ & $\begin{array}{lll}0 & & \\
\end{array}$ & 1 & 0 \\
\hline Blogs & $10 \mathrm{pts}$. & 0 & 0 & 0 & 1 & $\mathbf{0}$ & 0 & 0 \\
\hline $\begin{array}{l}\text { Sub total de } \\
\text { tecnologías } \\
\text { remotas }\end{array}$ & & 0 & 4 & 3 & 4 & 2 & 4 & 3 \\
\hline TOTAL & $\begin{array}{l}\text { Max.10 } \\
\text { pts. }\end{array}$ & 2 & 7 & 5 & 6 & 5 & 5 & 4 \\
\hline
\end{tabular}

Fuente: Elaboración propia, (2020).

\section{RESULTADOS Y DISCUSIÓN}

Los resultados sobre el uso de las tecnologías digitales en los museos más representativos de la ciudad de Lima, fueron moderados, considerando que ninguno llego a la puntuación máxima de 10 puntos. Además, se puede observar que el nivel de uso de tecnologías digitales in situ, es menor en comparación al nivel de uso de las tecnologías digitales vía remota (ver figura 5).

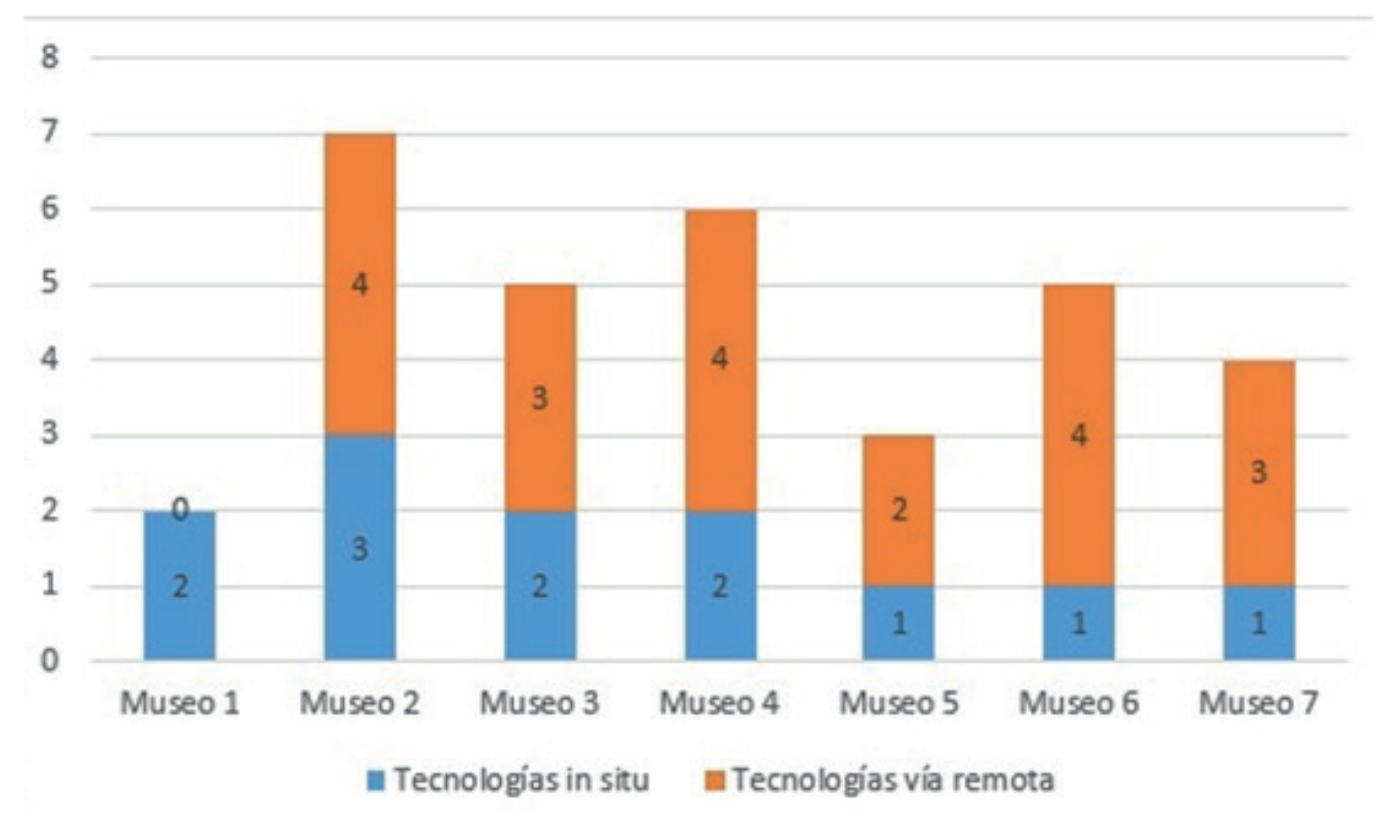

Fuente: Elaboración propia, (2020).

Figura 5. Resultados de los niveles de uso de las tecnologías digitales, en los museos más representativos de la ciudad de Lima. 
El museo número 1, obtuvo una puntuación de 2 puntos en el uso de las tecnologías in situ, y una puntuación de 0 puntos en el uso de tecnologías remotas, lo que da una puntuación total de 2 puntos (ver tabla 3). Lo que se interpreta como muy poco uso de las tecnologías digitales (ver tabla 4), lo que es realmente grave, considerando que es uno los museos más importantes de la ciudad de Lima. Lo que nos llamó la atención en este caso particular, fue que el museo no cuenta con ninguna tecnología de vía remota, lo que denotó su debilidad y falta de voluntad por tener presencia en el ciberespacio.

El museo número 2, obtuvo una puntuación de 3 puntos en el uso de las tecnologías in situ, y una puntuación de 4 puntos en el uso de las tecnologías remotas, lo que da una puntuación total de 7 puntos (ver tabla 3). Lo que se interpreta como buen uso de las tecnologías digitales (ver tabla 4). En este caso el museo demostró estar comprometido con la transformación digital. Además, el museo cuenta con aplicaciones digitales dentro de sus instalaciones y tiene presencia en el ciberespacio a través de sus múltiples opciones digitales.

El museo número 3, obtuvo una puntuación de 2 puntos en el uso de las tecnologías in situ, y una puntuación de 3 puntos en el uso de las tecnologías remotas, lo que da una puntuación total de 5 puntos (ver tabla 3). Lo que se interpreta como un uso moderado de las tecnologías digitales (ver tabla 4). Llama la atención, que el museo no cuente con página web.

El museo número 4, obtuvo una puntuación de 2 puntos en el uso de las tecnologías in situ, y una puntuación de 4 puntos en el uso de tecnologías remotas, lo que da una puntuación total de 6 puntos (ver tabla 3). Lo que se interpreta como un uso moderado de las tecnologías digitales (ver tabla 4). El museo presenta mayor fortaleza en la dimensión de tecnologías vía remota.

El museo número 5, obtuvo una puntuación de 3 puntos en el uso de las tecnologías in situ, y una puntuación de 2 puntos en el uso de tecnologías remotas, lo que da una puntuación total de 5 puntos (ver tabla 3). Lo que se interpreta como un uso moderado de las tecnologías digitales (ver tabla 4). Llama la atención, que el museo no cuente con página web.

El museo número 6, obtuvo una puntuación de 1 punto en el uso de las tecnologías in situ, y una puntuación de 4 puntos en el uso de las tecnologías remotas, lo que da una puntuación total de 5 puntos (ver tabla 3). Lo que se interpreta como uso moderado de las tecnologías digitales (ver tabla 4). Este museo mostró debilidad en el uso de tecnologías in situ, pero fortaleza en el uso de las tecnologías remotas, que le permiten tener presencia en el ciberespacio.

El museo número 7, obtuvo una puntuación de 1 punto en el uso de las tecnologías in situ, y una puntuación de 3 puntos en el uso de las tecnologías remotas, lo que da una puntuación total de 4 puntos (ver tabla 3). Lo que se interpreta como un poco uso de las tecnologías digitales (ver tabla 4). En este caso el museo mostró debilidad en el uso de tecnologías in situ, y un moderado uso de tecnologías remotas. 
Tabla 4. Equivalencia entre el puntaje y el nivel de uso de las tecnologias digitales

\begin{tabular}{cc} 
Puntaje & Nivel de uso \\
\hline 0 puntos & No hay uso \\
\hline $1-2$ puntos & Muy poco uso \\
\hline $3-4$ puntos & Poco uso \\
\hline $5-6$ puntos & Moderado uso \\
\hline $7-8$ puntos & Buen uso \\
\hline $9-10$ puntos & Excelente uso
\end{tabular}

Fuente: Elaboración propia, (2020).

\section{CONCLUSIONES}

Aún existen brechas digitales por subsanar en los museos más importantes de la ciudad de Lima. Si bien la economía es un factor limitante en la digitalización de los museos, también se deberán considerar otros factores intervinientes, como lo son la reticencia y letargo de los directores de los museos por abordar la transformación digital. Pensamos que, en esta era digital los museos deberían de gestionar diligentemente las acciones estratégicas correspondientes, que le permitan abordar cada vez mejor la transformación digital, sobre todo en sus procesos de comunicación, que son procesos medulares en la transmisión de la cultura de generación en generación, y que además son factor clave para el logro del cumplimiento de su misión institucional. Por lo tanto, los museos de la ciudad de Lima deberán replantearse y considerar la estrategia digital ya no como una opción, sino más bien como una necesidad que emerge acelerada y justificadamente en plena revolución digital.

\section{REFERENCIAS BIBLIOGRÁFICAS}

Alemán Carmona, A. M. (2006). Los museos como instrumentos educativos. Cultura(20),
14-30. http://www.revistacultura.com.pe/revistas/RCU_20_1_los-museos-como-instrumentos-educativos.PDF

Bauman, Z. (2013). La cultura en el mundo de la modernidad líquida. Buenos Aires: Fondo de la Cultura Económica.

Bemudez, P. (2018, 17 de marzo). Revolución digital. Gestión. https://gestion.pe/blog/revolucion-digital/2018/03/super-interesantes-cifras-de-la-penetracion-de-internet-y-facebook-en-el-peru-y-el-mundo.html/

Benito, M. F. (2019). El cosmonauta Ivan Istochnikov en la era de la postfotografía. Arte, Individuo y Sociedad, 31(3), 453-469. doi:https://doi.org/10.5209/aris.60549

Elisondo, R., \& Melgar, M. (2015, agosto). Museos y la Internet: contextos para la innovación. Innovación Educativa, 15(68), 1732. http://www.scielo.org.mx/pdf/ie/v15n68/ v15n68a3.pdf

Finlev, T., Maguire, R., Oppenheim, B., \& Skvirsky, S. (2017). El futuro de la economía na- 
ranja. Formulas creativas para mejorar vidas en América Latina y el Caribe. Palo Alto: BID.

García Canclini, N. R. (2019). Ciudadanos reemplazados por algoritmos. Alemania: Calas.

Gob.pe. (2020, 16 de abril). Plataforma digital única del Estado Peruano. https://www.gob.pe/institucion/cultura/ noticias/126024-ministerio-de-cultura-impulsa-visitas-online-a-sus-museos-virtuales

Hagedorn Saupe, M. (2014, 12 de agosto). Los museos en la era digital. https:// www.youtube.com/watch?v=6-8iYkled6Q

Instituto Nacional de Estadística e Informática. (2015, 26 de marzo). Población que utiliza internet incrementó frecuencia de uso. https://www.inei.gob.pe/prensa/noticias/ poblacion-que-utiliza-internet-incremento-frecuencia-de-uso-8275/\#: :text=E1\%20 INEI\%20inform $\% \mathrm{C} 3 \% \mathrm{~B} 3 \% 20$ que $\% 20 \mathrm{del}$,juegos\%20de\%20videos\%20y\%20obtener

Maceira, L. (2009, 10 de marzo). El museo: espacio educativo potente en el mundo contemporaneo. Sinéctica(32), 13-17. http:// www.scielo.org.mx/scielo.php?script=sci_arttext\&pid=S1665-109X2009000100007\&ln$\mathrm{g}=\mathrm{es} \& \operatorname{tlng}=\mathrm{es}$.

Mas Iglesias, J. M. (2018). Museos españoles en Facebook: análisis de su comunicación como museos sociales. Revista de Comunicación, 17(2), 185-207.doi:http://dx.doi.org/10.26441/RC17.2-2018-A8

Ministerio de Cultura. (2012). Guía de Museos del Perú. Lima. https://www.cultura. gob.pe/sites/default/files/paginternas/ta- blaarchivos/2013/09/guiamuseos191212.pdf Montiel, E. (2004). La diversidad cultural en la era de la globalización. Turismo y Patrimonio(4), 47-55.

Moreno, M. (2018). La enciclopedia del community manager. Barcelona: Deusto.

Mst, P. C. (2017). Los museos como mediadores de la memoria en la era digital. Índex, revista de arte contemporáneo(3), 22-30. http:// scielo.senescyt.gob.ec/scielo.php?script $=$ sci isoref\&pid=S2477-91992017000100022\&ln$\mathrm{g}=\mathrm{es} \& \operatorname{tlng}=\mathrm{es}$

Museo Histórico Nacional de Chile. (s.f.). Quiénes somos. Consultado el 5 de octubre del 2020. https://www.mhn.gob.cl/618/w3-propertyvalue-40743.html?_noredirect=1\#: :tex$\mathrm{t}=\mathrm{E} 1 \% 20 \mathrm{Museo} \% 20 \mathrm{Hist} \% \mathrm{C} 3 \%$ B3rico $\% 20$ Nacional\%20tiene,hasta $\% 201 \mathrm{a} \% 20 \mathrm{~d} \% \mathrm{C} 3 \%$ A9cada\%20de\%201970.

Museo Nacional de Arqueología, Antropología e Historia del Perú. (s.f.). Portal de transparencia. Consultado el 5 de octubre del 2020. https://mnaahp.cultura.pe/elmuseo/mision-vision\#: : text $=\% 2 \mathrm{D} \% 20$ Crear $\% 20$ conciencia $\% 20$ en $\% 201 \mathrm{a} \% 20$ comunidad,y $\% 20$ promoviendo $\% 201 \mathrm{a} \% 20$ ciudadan $\% \mathrm{C} 3 \% \mathrm{ADa} \% 20$ intercultural.

Museo Nacional de Historia Americana. (s.f.). Acerca del museo. Consultado el 5 de octubre del 2020. https://americanhistory.si.edu/visit/ espa $\% \mathrm{C} 3 \% \mathrm{~B} 1 \mathrm{ol} \#$ mission

Museo Nacional del Virreinato. (2019). El Museo. https://virreinato.inah.gob.mx/el-museo\#: : text=El $\% 20$ Museo $\% 20$ Nacional $\% 20$ del $\% 20$ Virreinato,de $\% 201 \mathrm{a} \% 20$ historia $\% 20$ 
de $\% 20 \mathrm{M} \% \mathrm{C} 3 \% \mathrm{~A} 9 \mathrm{xico.}$

Museo Nacional Thyssen Bornemisza. (2020). Portal de Transparencia. https://www.museothyssen.org/transparencia/mision-valores-normativa/vision

Negroponte, N. (1995). El mundo digital. Barcelona: Ediciones B,S.A.

Nuñez, A. (2007, enero). El museo como espacio de mediación: el lenguaje de la exposición museal. Universitas humanísticas(63), 181-199. Obtenido de http://www.scielo.org. co/pdf/unih/n63/n63a10.pdf

Reginald Murphy, A., \& Farmer Kevin. (2012). La misión del museo. Cultura y Desarrollo(8), 7-11. http://www.lacult.unesco.org/docc/mision_museos.pdf

Riofrío Flores, M. (2019). Agenda de sostenibilidad para los museos y centros expositivos de Lima: ruta para su incidencia en el desarrollo sostenible de la ciudad. (M. d. Lima, Ed.)

Senge, P. (2010). La quinta disciplina. Buenos Aires: GANICA S.A.

Zegarra, M. (2018, 29 de agosto). CADE Digital 2018: La transformación digital es ahora. Lima, Lima, Perú. https://www.youtube.com/

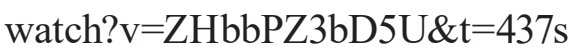

